\title{
Single cavity filters on end-faces of optical fibers
}

Meister, Stefan, Schweda, Dawid, Dziedzina, Marcus, AlSaadi, Aws, Franke, Bülent, et al.

Stefan Meister, Dawid Schweda, Marcus Dziedzina, Aws Al-Saadi, Bülent A. Franke, Chris Scharfenorth, Bernd Grimm, Daniela Dufft, Sigurd K. Schrader, Hans J. Eichler, "Single cavity filters on end-faces of optical fibers," Proc. SPIE 7579, Laser Resonators and Beam Control XII, 75791D (17 February 2010); doi: 10.1117/12.842519

SPIE. Event: SPIE LASE, 2010, San Francisco, California, United States 


\title{
Single cavity filters on end-faces of optical fibers
}

\author{
Stefan Meister*a , Dawid Schweda ${ }^{a}$, Marcus Dziedzina ${ }^{a}$, Aws Al-Saadi ${ }^{a}$, Bülent A. Franke ${ }^{a}$, \\ Chris Scharfenorth ${ }^{\mathrm{a}}$, Bernd Grimm ${ }^{\mathrm{b}}$, Daniela Dufft ${ }^{\mathrm{b}}$, Sigurd K. Schrader ${ }^{\mathrm{b}}$, Hans J. Eichler ${ }^{\mathrm{a}}$ \\ ${ }^{a}$ Technische Univ. Berlin, Institut für Optik und Atomare Physik, \\ ER1-1, Str. des 17. Juni 135, 10623 Berlin, Germany; \\ ${ }^{\mathrm{b}}$ Technische Fachhochschule Wildau, Instituts für Plasma- und Lasertechnik, Bahnhofstr. \\ 15745 Wildau, Germany
}

\begin{abstract}
We have developed thin film Fabry-Perot filters directly coated on optical fibers to archive a high level of integration with a reduction of optical elements. Such band-pass filters can be used in fiber optical sensor systems, and for fiber communication, e.g. CWDM applications.

The filters cavities consist of a single spacer and two dielectric mirrors. The dielectric mirrors are deposited by PVD directly on end-faces of single-mode optical fibers. Dielectric as well as polymeric materials were applied as the spacer layer. Polymeric spacer layers were deposited by dip coating.

The influence of the mirror reflectivity on the transmission band of the Fabry-Perot filters was investigated. Furthermore, the optical performance of filters with first order $(\lambda / 2)$ as well as higher order spacers was analyzed. The experimental results are compared with numerical analysis of Fabry-Perot cavities on the end-face of cylindrical waveguides. The spectral characteristic of the filters are calculated using a software solving Maxwell's equations by a FDTD method.

The layer design of the filters and the deposition process were optimized for maximum transmission and narrow bandwidth of the transmission peak. Passive band-pass filters on fiber end-faces were designed, fabricated and characterized for transmission wavelengths of $945 \mathrm{~nm}, 1300 \mathrm{~nm}$, as well as $1550 \mathrm{~nm}$. Bandwidths as narrow as $1 \mathrm{~nm}$ could be achieved for $945 \mathrm{~nm}$.
\end{abstract}

Keywords: fiber optics, microcavity, optical coating, band-pass filter, Fabry-Perot filter, dip coating

\section{INTRODUCTION}

Optical sensors are widely used in biological, chemical, and environmental applications as well as in monitoring the condition of civil constructions ${ }^{1}$. In such systems, wavelength monitors are needed which are inexpensive, compact, and highly reliable. A promising approach relies on wavelengths dependent transmission of spectral filters. Thin film FabryPerot interferometers are well suited as narrow band-pass filters ${ }^{2}$. In sensing applications, Fabry-Perot filters are used in combination with photodiodes to detect sensor respond signals.

Furthermore, in fiber optical communication system, Fabry-Perot filters are used for channel selection or side band suppression in, e.g. CWDM applications ${ }^{3}$.

We have developed thin film Fabry-Perot filters, which act as narrow band-pass filters directly coated on fiber end-faces. This is to achieve a very high level of integration with a reduction of optical elements. Such filters have the potential for mass production because of the very small fiber cross-section.

In this paper, different Fabry-Perot filters on fiber end-faces, containing a single spacer, were investigated, which are designed for different wavelengths, e.g. $945 \mathrm{~nm}, 1300 \mathrm{~nm}$ and $1550 \mathrm{~nm}$. The fabrication and the optical characteristics of passive Fabry-Perot filters on fiber end-faces with dielectric as well as polymeric spacer will be shown.

Fabry-Perot filter with dielectric spacer material are deposited on fiber end-faces to investigate the influence of the mirror reflectivity on transmission band of the filters. Furthermore, by applying a polymeric spacer in the Fabry-Perot structure, the spectral characteristics of higher order filter cavities on fiber end-faces were investigated.

*smeister@physik.tu-berlin.de; phone: +49-30-31426227; fax: +49-30-31426888

Laser Resonators and Beam Control XII, edited by Alexis V. Kudryashov, Alan H. Paxton, Vladimir S. Ilchenko, Lutz Aschke, Proc. of SPIE Vol. 7579, 75791D · C 2010 SPIE · CCC code: 0277-786X/10/\$18 · doi: 10.1117/12.842519 


\section{FILTER COATINGS ON FIBER END-FACES}

In this section, the deposition of optical layers on fiber end-faces, which form Fabry-Perot filters, will be described. The filters consist of two dielectric mirrors and a spacer between them. Dielectric as well as polymeric spacers are investigated. In any case, the deposition process of the layer system starts with the first dielectric mirror.

\subsection{Dielectric coatings on fiber end-faces}

For fiber preparation prior deposition of the first mirror, the fibers were cleaved. After cleaving, the fiber end-faces were subjected to multi-step cleaning procedures. Wet chemical as well as high electric field cleaning procedures were tested to achieve coatings with highest quality. Further details about the preparation of the fiber end-faces prior coating are described elsewhere ${ }^{4}$. Methods to increase the adherence of the coatings on the fiber end-faces and to achieve high damage thresholds are described in Meister et al. ${ }^{5,6}$.

For dielectric mirror fabrication, fiber end-faces are coated with quarter wave layers consisting of $\mathrm{Ta}_{2} \mathrm{O}_{5}$ and $\mathrm{SiO}_{2}$ deposited by electron-beam evaporation with a deposition rate of $0.5 \mathrm{~nm} / \mathrm{s}$. If a dielectric spacer is applied, the spacer consists of $\mathrm{SiO}_{2}$ with a thickness of two quarter wave layers, corresponding to a first order spacer with a thickness of $\lambda / 2$. In this case, the whole layer system of the Fabry-Perot filter is deposited in one run.

Figure 1a shows a scanning electron microscope (SEM) image of a fiber end-face coated with a Fabry-Perot filter consisting of 44 quarter wave layers, including the dielectric spacer, with an overall physical thickness of $\sim 6 \mu \mathrm{m}$. This dielectric filter is designed for a wavelength of $945 \mathrm{~nm}$. It is shown that the coating is well attached on the fiber surface even on the edge of the end-face. The indentation on the right side of the coated end-face results from the fiber cleave. Figure $1 \mathrm{~b}$ shows a side view of the coating on the edge of the fiber end-face. The interface between coating and fiber can be identified (horizontal groove).

The deposition direction is from the top in this figure. It was found that a thin layer is grown around the fiber on the fiber cladding, although the deposition angle is here around $90^{\circ}$. This layer is seen in figure $1 \mathrm{~b}$ below the interface. The surface of the coating appears smooth on the top, and strongly columnar on the side.

a)

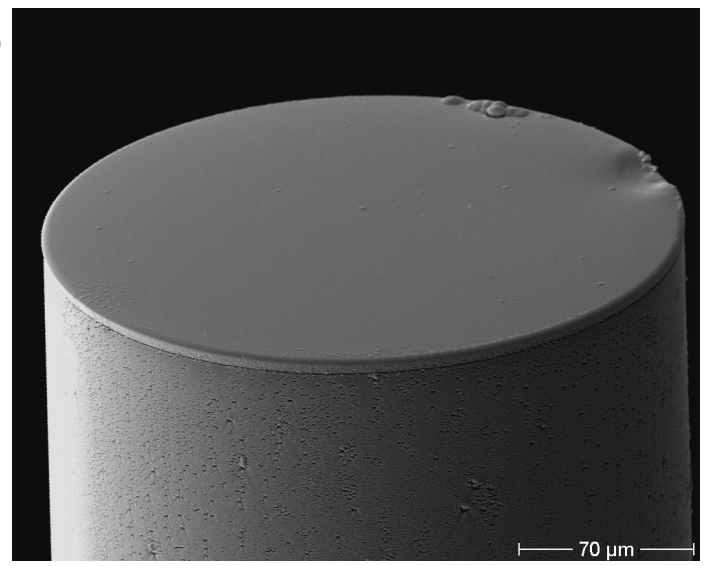

b)

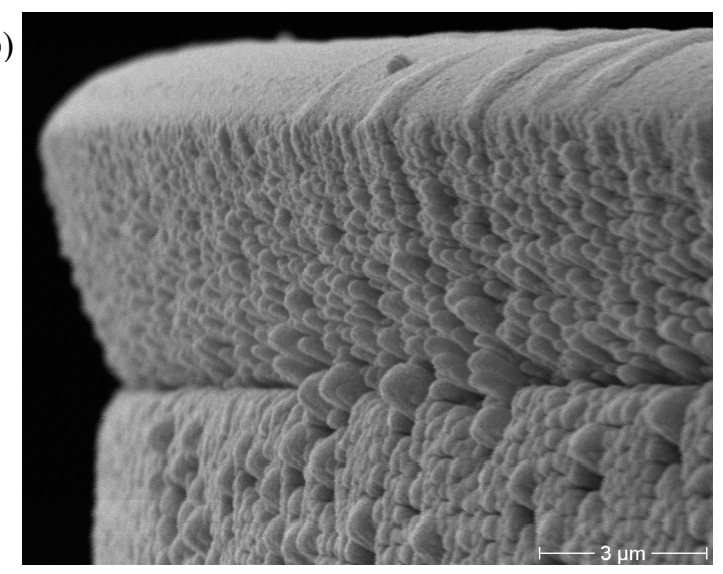

Figure 1. SEM image of a) the entire end-face of a optical fiber coated with a stack of 44 quarter wave layers, and b) side view of this filter-coating (physical thickness $\sim 6 \mu \mathrm{m}$ ) and its interface with the fiber. The adhesion of the coating is increased by an additional buffer layer.

Absorption losses in Fabry-Perot filters are a very important issue. Even very small k-values of the coating materials can lead to significant transmission losses due to the multiple reflections in the filters. The coated fibers are tempered at $150^{\circ} \mathrm{C}$ to decrease stoichometeric defects in the $\mathrm{Ta}_{2} \mathrm{O}_{5}$ layers and to reduce the absorption to $k=3.8^{*} 10^{-5}$ at a wavelength of $945 \mathrm{~nm}$. 


\subsection{Polymeric coatings on fiber end-faces}

The so far single dielectric $\lambda / 2$ spacer in between the two dielectric mirrors is now substituted by a polymeric layer, which can have higher order $(m * \lambda / 2$, with $m$ is an integer) thicknesses. That means multiple transmission peaks within the high reflective range of the mirror spectrum can be achieved (see figure $5 \mathrm{~b}$ ). The most important properties of such higher order polymeric Fabry-Perot filters are the free spectral range (FSR), the width of the transmitted peaks $(-3 \mathrm{~dB}$ bandwidth) and the losses due to absorption and beam divergence ${ }^{7}$.

The well known polycarbonate (PC) was chosen as spacer material. The chemical structure is shown in figure 2. It shows a high transparency for the desired wavelengths, good mechanical properties, and with a glass transition temperature of $150^{\circ} \mathrm{C}^{8}$ it is well suited for the PVD process when evaporating the (second) dielectric mirror. In addition, a guest polymer can be implemented in PC, which exhibit an electro-optical effect.

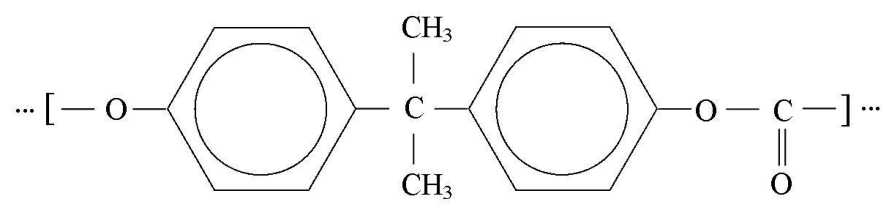

Figure 2. Chemical structures of polycarbonate.

Polycarbonate granules were solved in 1,1,2,2-Tetrachloroethane $\left(\mathrm{CHCl}_{2}\right)_{2}$. The fiber end-faces were dipped in the solvent for $10 \mathrm{~s}$ and dried afterwards in a vacuum oven below $4 \mathrm{mbar}$ at a temperature of $70^{\circ} \mathrm{C}$ for minimum 30 minutes. Different concentrations of the polycarbonate, from $50 \mathrm{mg} / \mathrm{ml}$ to $200 \mathrm{mg} / \mathrm{ml}$, were investigated, see table 1 .

Table 1. Layer thickness and shape of the polycarbonate coatings in dependency of the PC concentration in the solvent 1,1,2,2-Tetrachloroethane

\begin{tabular}{|c|c|c|}
\hline $\begin{array}{l}\text { Polycarbonate } \\
\text { concentration }[\mathrm{mg} / \mathrm{ml}]\end{array}$ & $\begin{array}{l}\text { Layer thickness above } \\
\text { the fiber core }[\mu \mathrm{m}]\end{array}$ & $\begin{array}{l}\text { Shape of the polymeric } \\
\text { layer on the fiber end-face }\end{array}$ \\
\hline 50 & 1.7 & concave \\
\hline 100 & 2.8 & convex \\
\hline 150 & 4.5 & convex \\
\hline 200 & 5.3 & convex \\
\hline
\end{tabular}

The thickness of the polymeric coating above the fiber core was measured optically, while the shape was scanned by an Atomic Force Microscope (AFM). Apparently, the layer thickness increases with higher PC concentrations, e.g. $2.8 \mu \mathrm{m}$ with $100 \mathrm{mg} / \mathrm{ml}$ and $5.3 \mu \mathrm{m}$ with $200 \mathrm{mg} / \mathrm{ml}$. It can be concluded that an adjustment of the spacer thickness can be achieved by varying the PC concentration.

An AFM-scan of a fiber end-face dipped in a solvent with a $100 \mathrm{mg} / \mathrm{ml} \mathrm{PC}$ concentration is shown in figure 3 . The coating has a convex shape with a satisfactory homogenous thickness above and nearby the fiber core, which decreases radial to the edge. Similar coating shapes were measured with higher PC concentrations. The surface of the polymer coatings shows a RMS-roughness of less than $1 \mathrm{~nm}$.

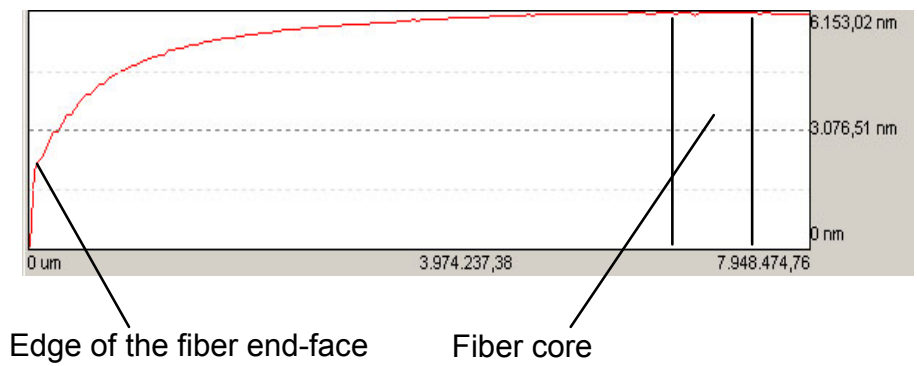

Figure 3. Line scan (AFM) of a dip coated fiber end-face in a solvent with a PC concentration of $100 \mathrm{mg} / \mathrm{ml}$ (convex shape). 
A significant difference in the layer shape was observed for the lowest PC concentration of $50 \mathrm{mg} / \mathrm{ml}$. Also in this case the coating has a satisfactory homogenous thickness of $1.7 \mu \mathrm{m}$ above and nearby the fiber core, the thickness increases radial to the edge though, forming a concave shape, see figure 4.

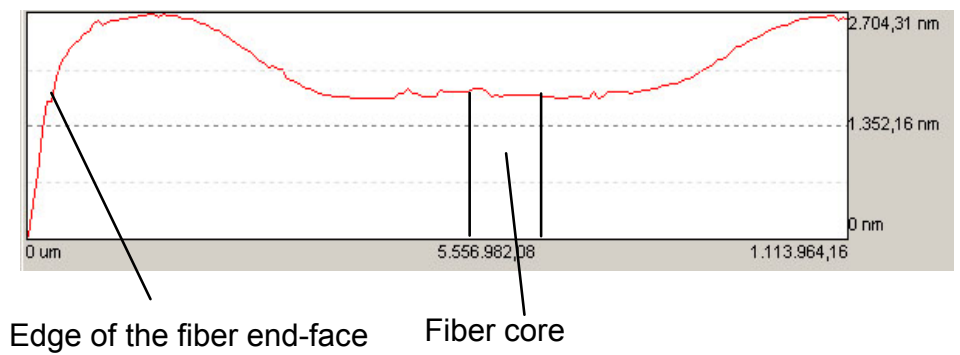

Figure 4. Line scan (AFM) of a dip coated fiber end-face in a solvent with a PC concentration of $50 \mathrm{mg} / \mathrm{ml}$ (concave shape).

To build up a complete Fabry-Perot filter with a polymeric spacer, the first steps, from cleaving to cleaning the fiber end-face and coating the first dielectric mirror were similar to the processes described for solely dielectric filters. Changes had to be made in the choice of the mirror parameters since the filter peaks should be geared to wavelengths of about $1550 \mathrm{~nm}$. The polymer was dip coated in the previously described procedure and finally the second dielectric mirror was evaporated. A scheme of a finished passive Fabry-Perot filter with a polymeric spacer is pictured in figure 5a. Figure $5 \mathrm{~b}$ shows a SEM image of a PC coated fiber end-face. It is seen that the PC coating is homogeneous distributed on the fiber end-face.
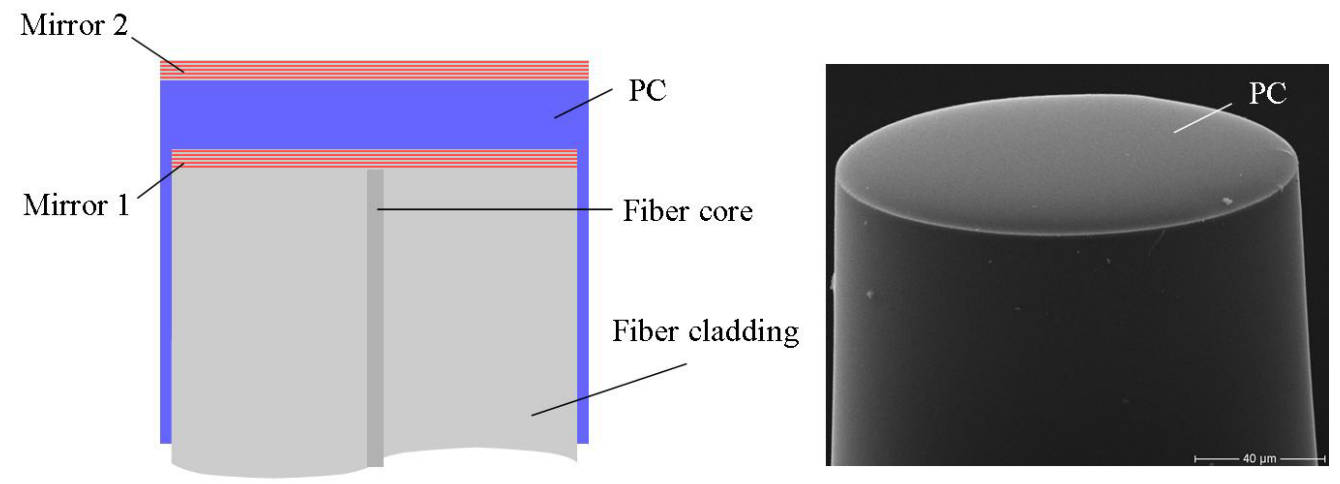

a)

b)

Figure 5. a) Scheme of the hybrid layer design of the Fabry-Perot filter on an end-face of a single mode fiber. b) SEM image of a polycarbonate coated fiber end-face.

\section{SIMULATION OF FABRY-PEROT FILTERS ON FIBER END-FACES}

The spectral transmission function of the filters depending on the design parameters are calculated by an analysis based on a Finite-Difference-Time-Domain (FDTD) method using FullWAVE software provided by RSoft. 3-D calculations were performed for Fabry-Perot filters on fiber end-faces. The construction of a filter on a fiber core is shown in figure 6a. The calculation domain size in $\mathrm{x}$ and $\mathrm{y}$ direction was chosen to be $\pm 20 \mu \mathrm{m}$, which is larger than the $9 \mu \mathrm{m}$ fiber core diameter to cover the evanescent field propagation outside of the fiber core as well as the divergent field in the filter extended by multiple reflections. The used uniform grid size in $\mathrm{x}, \mathrm{y}$, and $\mathrm{z}$ was $0.05 \mu \mathrm{m}$, respectively, and the time step for satisfying the Courant stability conditions was $0.028 \mathrm{ct}$. The method of pulse excitation and subsequent Fourier analysis of the transmitted pulse was used to calculate the spectral characteristics of the Fabry-Perot filters on fiber endfaces. A characteristic spectrum of a filter with higher order $\left(8^{\text {th }}\right.$ order $)$ spacer designed for $1.55 \mu \mathrm{m}$ wavelength is shown 
in figure $6 \mathrm{~b}$. This filter had a layer stack $(\mathrm{HL})^{6} \mathrm{HLL}(\mathrm{HL})^{6} \mathrm{H}$, where $\mathrm{H}$ indicates high-index and $\mathrm{L}$ indicates low-index quarter wave layers, and a spacer of $3.974 \mu \mathrm{m}$ physical thickness. The spacer material has a refractive index of $\mathrm{n}=1.56$.

a)

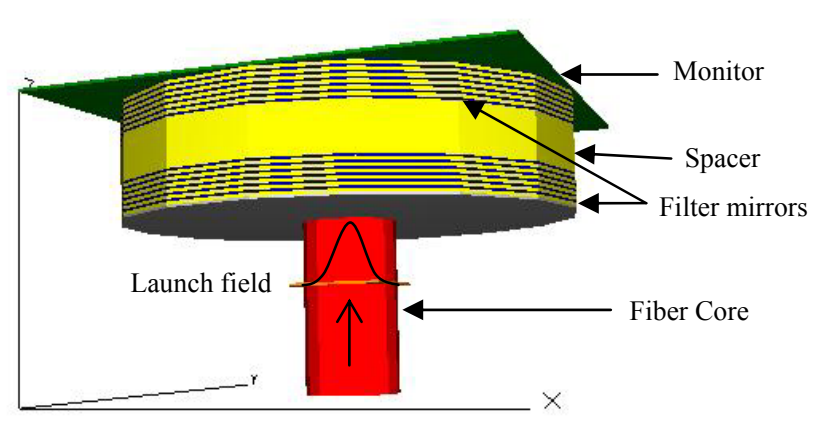

b)

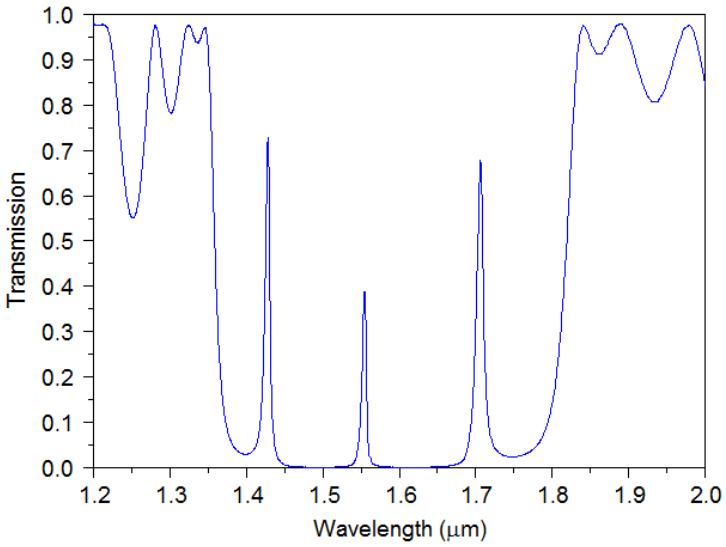

Figure 6. a) Scheme of the simulation construction of a Fabry-Perot filter on the end-face of a single-mode fiber.

b) Characteristic spectrum of high order Fabry-Perot filter with a physical spacer thickness of $3.974 \mu \mathrm{m}$ at $1.55 \mu \mathrm{m}$ wavelength.

The chosen quantization in time and space, mandatory for the simulation, introduce losses to the filter. Those losses may not have the same value as in the real Fabry-Perot filter. But, if the filter parameters are changed, its influence on the filter losses will have the same trend.

\section{SETUP FOR OPTICAL CHARACTERISATION OF FABRY-PEROT FILTERS ON FIBER END-FACES}

The transmission spectra of the Fabry-Perot filters directly coated on the fiber end-faces of single-mode fibers are investigated. The filters are designed for a wavelength of $945 \mathrm{~nm}, 1300 \mathrm{~nm}$, and $1550 \mathrm{~nm}$, respectively. The experimental setup for the transmission measurements is shown in figure 7.

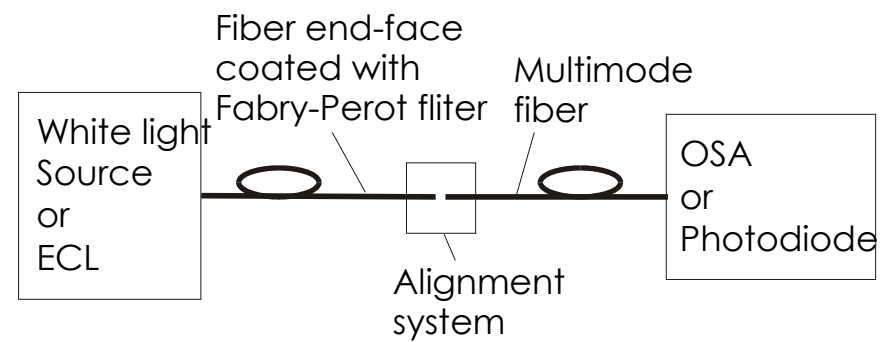

Figure 7. Experimental setup for transmission measurements of Fabry-Perot filters directly coated on end-faces of optical fibers.

The optical performance of the filter-coatings was analyzed by either, an Optical Spectrum Analyzer (OSA) in combination the with a white light source providing a broad spectral range from $600 \mathrm{~nm}$ to $1700 \mathrm{~nm}$, or by means of an External Cavity Laser (ECL) in combination with a calibrated diode.

In the transmission measurements, the spectral transmission losses of the filter were estimated by using an uncoated multimode fiber as collector (a fiber with a core diameter of $62.5 \mu \mathrm{m}$ ) precisely aligned close to the coated fiber endface. Therefore, the whole divergent transmitted beam is coupled in this fiber. Afterwards, the spectral transmission was compared to the spectral intensity of the light transmitted through a similar, but uncoated fiber. 


\section{RESULTS AND DISCUSSION}

\subsection{Dielectric Fabry-Perot filter on fiber end-faces}

Fabry-Perot filters containing a single dielectric $\lambda / 2$ spacer coated on the fiber end-faces are first considered. Filters with different numbers of $\lambda / 4$ layers in the mirror stacks are investigated, which corresponds to a change of the reflectivity of the filter mirrors. Figure 8a shows the transmission spectrum of a Fabry-Perot filter directly coated on a fiber end-face as well as the white light spectrum (upper line) transmitted through a comparable but uncoated fiber. The layer stack of this filter was $(\mathrm{HL})^{7} \mathrm{HLL}(\mathrm{HL})^{7} \mathrm{H}$, where $\mathrm{H}$ indicates high-index and $\mathrm{L}$ indicates low-index quarter wave layers. The two subsequent quarter wave layers, $\mathrm{LL}$, correspond to the half wave spacer. The $-3 \mathrm{~dB}$ bandwidth of the transmission peak is $2.2 \mathrm{~nm}$. The transmission loss of the filter is $1.2 \mathrm{~dB}$. The filter contrast is more than $15 \mathrm{~dB}$. Figure $8 \mathrm{~b}$ shows the transmission spectrum of a Fabry-Perot filter on a fiber end-face with a layer stack $(\mathrm{HL})^{8} \mathrm{HLL}(\mathrm{HL})^{8} \mathrm{H}$. The two additional layers in each mirror increase the reflectivity and, as a result, the bandwidth is narrowed to $1.3 \mathrm{~nm}$. The filter's transmission loss is increased to $2.2 \mathrm{~dB}$.
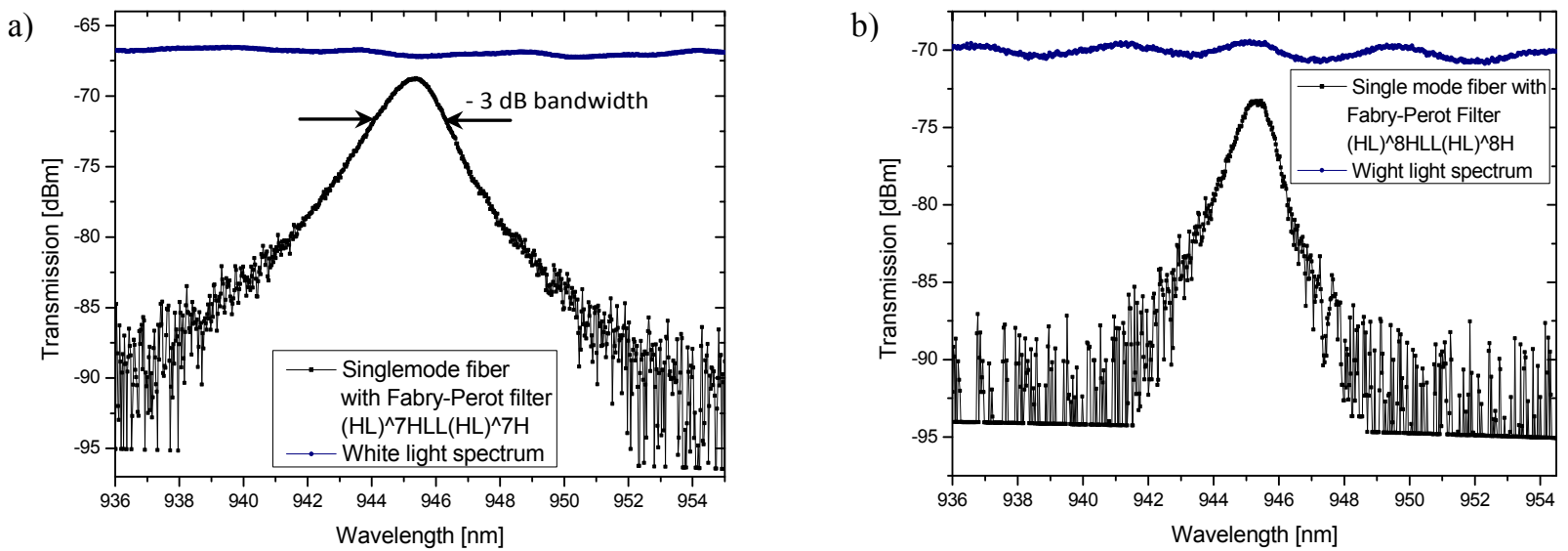

Figure 8. Transmission spectra of band-pass filters directly coated on the end-faces of SMF28 fibers as well as the white light spectra as reference. a) Filter $(\mathrm{HL})^{7} \mathrm{HLL}(\mathrm{HL})^{7} \mathrm{H}$ with a $-3 \mathrm{~dB}$ bandwidth of $2.2 \mathrm{~nm}$ and transmission loss of $1.2 \mathrm{~dB}$. b) Filter $(\mathrm{HL})^{8} \mathrm{HLL}(\mathrm{HL})^{8} \mathrm{H}$ with a $-3 \mathrm{~dB}$ bandwidth of $1.3 \mathrm{~nm}$ and transmission loss of $2.2 \mathrm{~dB}$.

Starting with the layer stack $(\mathrm{HL})^{6} \mathrm{HLL}(\mathrm{HL})^{6} \mathrm{H}$, the reflectivity was successively increased by additional pairs of high and low index layers. The results of the transmission measurements of such filters are summarized in table 2.

Table 2. Transmission $-3 \mathrm{~dB}$ bandwidths and filter losses at $945 \mathrm{~nm}$ wavelength depending on the layer stack of Fabry-Perot filters on fiber end-faces

\begin{tabular}{|c|c|c|c|c|}
\hline Filter layer stack & $\begin{array}{c}\text { Measured } \\
\text { bandwidth [nm] }\end{array}$ & $\begin{array}{c}\text { Calculated } \\
\text { bandwidth [nm] }\end{array}$ & $\begin{array}{c}\text { Measured } \\
\text { filter losses [dB] }\end{array}$ & $\begin{array}{c}\text { Calculated } \\
\text { filter losses [dB] }\end{array}$ \\
\hline$(\mathrm{HL})^{6} \mathrm{HLL}(\mathrm{HL})^{6} \mathrm{H}$ & 4.5 & 4.50 & 0.8 & 0.45 \\
\hline$(\mathrm{HL})^{7} \mathrm{HLL}(\mathrm{HL})^{7} \mathrm{H}$ & 2.2 & 2.21 & 1.2 & 0.78 \\
\hline$(\mathrm{HL})^{8} \mathrm{HLL}(\mathrm{HL})^{8} \mathrm{H}$ & 1.3 & 1.15 & 2.2 & 1.45 \\
\hline$(\mathrm{HL})^{9} \mathrm{HLL}(\mathrm{HL})^{9} \mathrm{H}$ & 0.9 & 0.68 & 3.8 & 3.23 \\
\hline$(\mathrm{HL})^{10} \mathrm{HLL}(\mathrm{HL})^{10} \mathrm{H}$ & 0.7 & 0.51 & 9.5 & 8.2 \\
\hline
\end{tabular}

It is shown that the $-3 \mathrm{~dB}$ bandwidths decrease with additional layer pairs, corresponding to higher mirror reflectivities. Bandwidths as narrow as $0.7 \mathrm{~nm}$ could be achieved for Fabry-Perot filters on fiber end-faces with a layer stack $(\mathrm{HL}){ }^{10} \mathrm{HLL}(\mathrm{HL}){ }^{10} \mathrm{H}$. In table 2 also the calculated bandwidths ${ }^{4}$ of the Fabry-Perot filters are listed.

For the first three filters listed in table 2, with low number of layers, the bandwidth narrows by a factor of about 2 , if two layers are added to the mirrors, respectively. Considering the last two filters, the bandwidth starts to get saturated. That effect can be explained by the strong increase of losses with higher number of layers, also shown in table 2 . An increase 
of losses limits the field confinement in the filter cavity and, therefore, the finesse of the filter and the filter bandwidth, respectively. The filter losses are induced not only by absorption in the coating layers. Also the divergent output beam of the single-mode fiber has to be considered ${ }^{4}$. This leads to a spatial walk-off of the beam in the filter, thus limiting the number of possible interferences.

Figure 9 shows a Fabry-Perot filter with a layer stack $(\mathrm{HL})^{7} \mathrm{HLL}(\mathrm{HL})^{7} \mathrm{H}$ designed for a peak wavelength of $1270 \mathrm{~nm}$. The measured transmission band, figure $9 \mathrm{a}$, has a $-3 \mathrm{~dB}$ bandwidth of $4.9 \mathrm{~nm}$. That agrees well with the bandwidth of the simulated transmission spectrum of $4.8 \mathrm{~nm}$, shown in figure $9 \mathrm{~b}$. The filter losses were determined to $2.3 \mathrm{~dB}$ compared to $1.85 \mathrm{~dB}$ losses in the calculated case.
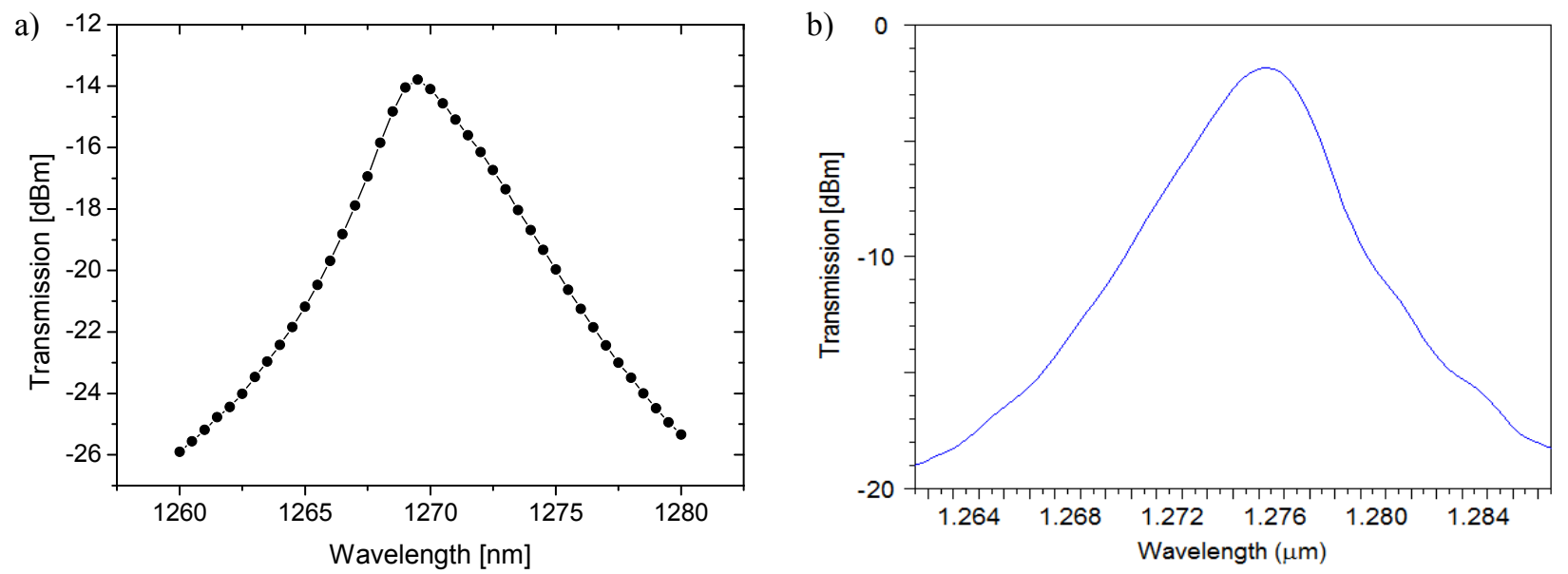

Figure 9. a) Transmission spectrum of a band-pass filter directly coated on the end-face of a SMF28 single-mode fiber. The filter with a layer stack $(\mathrm{HL})^{7} \mathrm{HLL}(\mathrm{HL})^{7} \mathrm{H}$ has a $-3 \mathrm{~dB}$ bandwidth of $4.9 \mathrm{~nm}$ and transmission loss of $2.3 \mathrm{~dB}$. b) Simulated transmission band with $4.8 \mathrm{~nm}$ bandwidth and $1.85 \mathrm{~dB}$ filter loss.

\subsection{Fabry-Perot filters on fiber end-faces with polymeric spacer}

In comparison to the solely dielectric Fabry-Perot filters containing a single dielectric $\lambda / 2$ spacer, one can achieve easily much higher spacer thicknesses with the polymer layer. By increasing the spacer thickness, higher order cavities in the Fabry-Perot filter can be achieved.
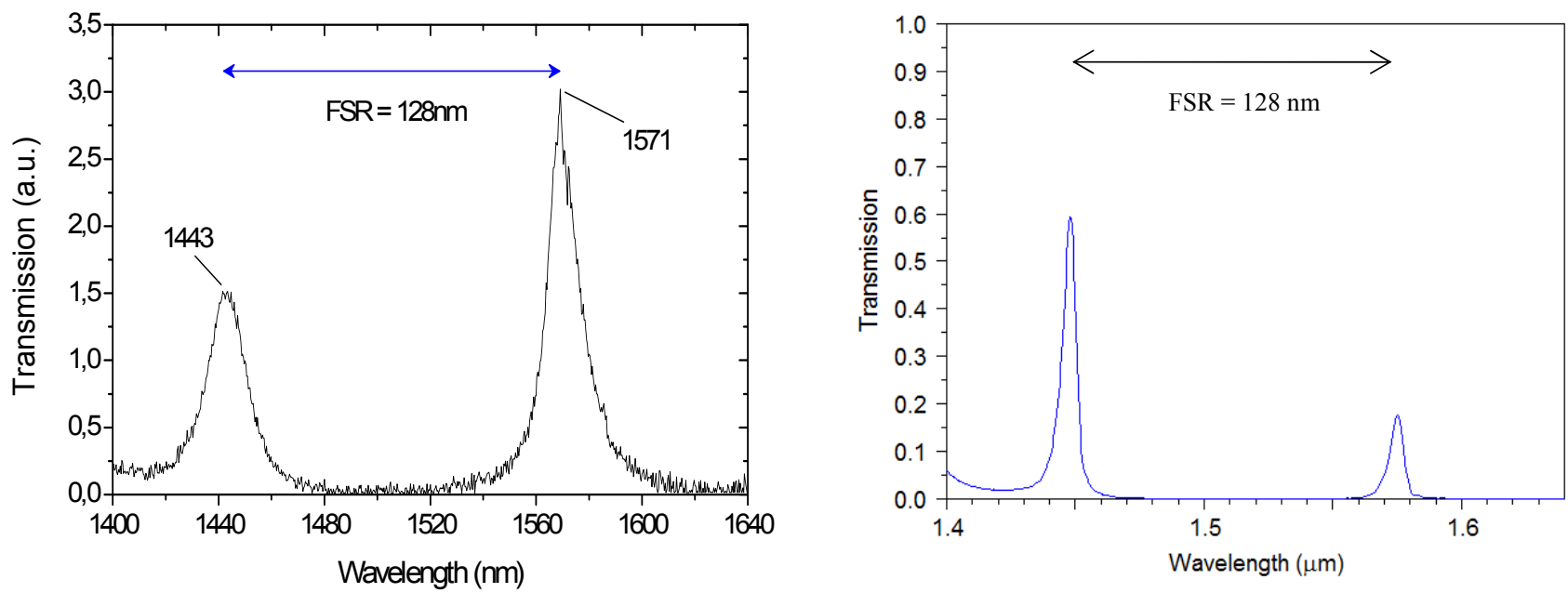

Figure 10. a) Measured spectrum of a Fabry-Perot filter with polymeric spacer. b) Simulated spectrum at a center wavelength of $1570 \mathrm{~nm}$ and a spacer thickness of $4.03 \mu \mathrm{m}$. 
Figure 10a shows a transmission spectrum of a Fabry-Perot filter with polymeric spacer on the fiber end-face illuminated by a white light source. Transmission peaks at $1443 \mathrm{~nm}$ and $1571 \mathrm{~nm}$ were measured corresponding to a free spectral range of FSR $=128 \mathrm{~nm}$. Obviously, on the small dimensioned fiber end-face, a mechanical measuring method of the spacer thickness determination within tolerable error limits would not be satisfying. Therefore, to estimate the spacer thickness, the previously described simulation was used by adjusting the order of the cavity and the center wavelength. A simulated approximation of the measurement results is shown in figure $10 \mathrm{~b}$ with a FSR $=128 \mathrm{~nm}$. It contains an $8^{\text {th }}$ order spacer at a center wavelength of $1570 \mathrm{~nm}$, i.e. a physical spacer thickness of $4.03 \mu \mathrm{m}$ (considering the refractive index of $\mathrm{PC}$ is $\mathrm{n}=1.56)$.

The transmission band of the $1571 \mathrm{~nm}$ peak was then measured by means of an ECL in combination with a diode detector. The resulting spectrum is shown in figure 11. The $-3 \mathrm{~dB}$ bandwidth of this peak was determined to be $9 \mathrm{~nm}$.

The simulated $-3 \mathrm{~dB}$ bandwidth of the same peak is with $6 \mathrm{~nm}$ smaller than the measured one. A peak-to-valley contrast of $15 \mathrm{~dB}$ was measured.

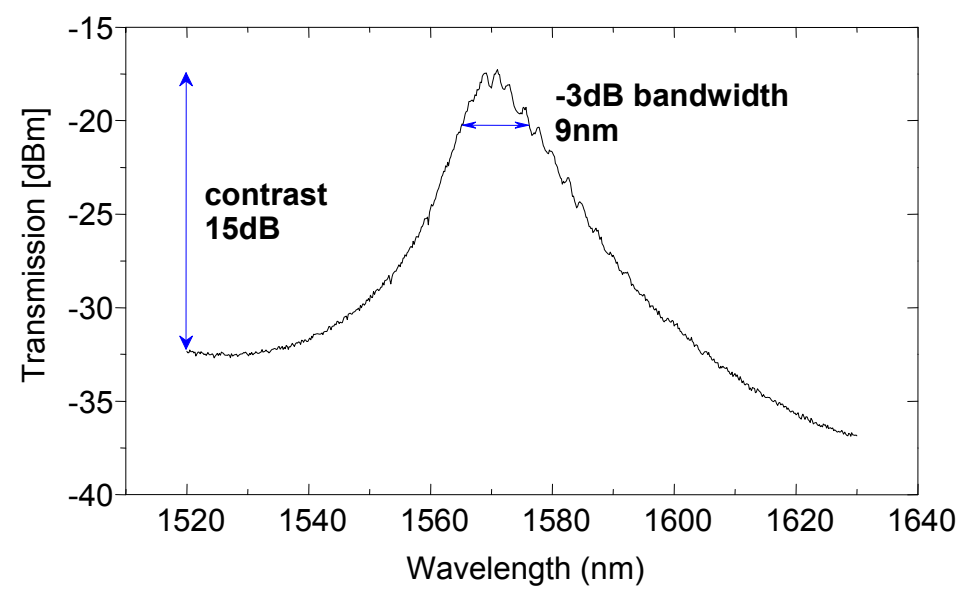

Figure 11. Measured transmission peak at $1571 \mathrm{~nm}$ with a $-3 \mathrm{~dB}$ bandwidth of $9 \mathrm{~nm}$ and a contrast of $15 \mathrm{~dB}$.

\section{SUMMARY}

Fabry-Perot filters coated on fiber end-faces with dielectric first order spacers and overall up to 36 quarter wave layers, corresponding to a layer stack $(\mathrm{HL})^{8} \mathrm{HLL}(\mathrm{HL})^{8} \mathrm{H}$, are well suited as band-pass filters for fiber optical applications.

The layer design of the filters and the deposition process were optimized for maximum transmission, and narrow bandwidth of the transmission peak. Band-pass filters fabricated for a transmission wavelength of $945 \mathrm{~nm}$ show maximum transmission values of up to $90 \%$. Bandwidths as narrow as $1 \mathrm{~nm}$ could be achieved.

Deposition of polymeric layers on the end-faces of optical fibers can be used as higher order spacers in the Fabry-Perot structure. A layer thickness of about $4 \mu \mathrm{m}$ corresponding to an $8^{\text {th }}$ order spacer at $1570 \mathrm{~nm}$ wavelength was realized, which has a $-3 \mathrm{~dB}$ bandwidth of $9 \mathrm{~nm}$.

\section{ACKNOWLEGEMENT}

This work is supported by BMBF/VDI in the frame of project 13N9635.

Special thanks to Christian Meuer from the Institut für Festkörperphysik of TU Berlin for support and discussions.

\section{REFERENCES}

1. Lee, B., "Review of the present status of optical fiber sensors", Optical Fiber Technology, 9, 57, (2006).

2. Macleod, H. A., [Thin film optical filters], Third Ed., IOP Publishing Bristol, (2001). 
3. Vanghaus, H., [Wavelength filters in fibre optics], Springer series in optical sciences, Springer Verlag, (2006).

4. Meister, S., [Functional optical coatings on fiber end-faces], Mensch \& Buch Verlag (mbv), Berlin, (2009).

5. Meister, S., Riesbeck T. and Eichler, H. J., "Glass fibers for stimulated Brillouin scattering and phase conjugation", Laser and Particle Beams, 25(1), 15, (2007).

6. Meister, S., Theiss, C., Scharfenorth, C. and Eichler, H. J., "Power Transmission Limits of Different Glass Fibers with Antireflective Coating", Proc. SPIE, 6193, 619310-1, (2006).

7. Meister, S., Franke, B. A., Dziedzina, M., Schweda, D., Scharfenorth, C. and Eichler, H. J., "Bandpass Filters on End-Faces of Optical Fibers", Proc. of the $35^{\text {th }}$ European Conference on Optical Communication (ECOC), P1.21, (2009).

8. Lide, D. R., [Handbook of Chemistry and Physics], $88^{\text {th }}$ Ed., CRC Press, 13-10, (2007). 